\title{
MORAL E COTIDIANO: VADIAGEM E PROSTITUIÇÃO NO DEPARTAMENTO DO ALTO ACRE (1904-1920)
}

\author{
Francisco Bento da Silva \\ Universidade Federal do Acre - Brasil
}

\section{RESUMO}

Este artigo tem como finalidade fazer uma abordagem sobre a vadiagem e a prostituição no Departamento do Alto Acre, no período de 1904 a 1920, a partir de fontes documentais como jornais, inquéritos policiais e processos criminais. Abordando crimes como vadiagem, embriaguez, crimes contra a honra e moral e bons costumes. Procuramos articular esses crimes e transgressões com a vida cotidiana da sociedade do Departamento do Alto Acre neste período, tentando dialogar e trazer um novo olhar para essas questões que são pouco exploradas.

PALAVRAS-CHAVE: Departamento do Alto Acre. Crimes. Vadiagem. Prostituição. Processos criminais.

\section{Introdução}

O Acre territorial, no período que vai do momento de sua organização política (1904) até ao fim dos Departamentos (1920) é marcado pelo poder governativo-administrativo descentralizado e exercido pelos prefeitos departamentais (Alto Acre, Alto Purus, Alto Juruá e Alto Tarauacá), nomeados diretamente pelo presidente da república e vinculados ao Ministério da Justiça e Negócios Interiores. Na prática o Acre era administrado diretamente pela União, através de seus prepostos designados para exercerem o poder executivo na nova unidade administrativa brasileira. Estabelecem-se os órgãos da justiça (poder judiciário) e o executivo procura outorgar, através de Decretos exarados pelos prefeitos, determinadas formas de controle expressas em medidas normativas e restritivas aos comportamentos e modos de vidas vistos como inadequados aos espaços públicos das incipientes cidades e núcleos urbanos que começavam a surgir (SILVA, 2013). 
Essa preocupação das autoridades é mais incisiva em relação a determinados grupos sociais e sujeitos considerados potencialmente perigosos à ordem estabelecida. Isso é algo que antecede o período em que estamos vinculando nossa pesquisa se pensarmos o contexto brasileiro da virada do XIX para o XX, principalmente na capital da República: a cidade do Rio de Janeiro. Havia por parte das autoridades a crença de que eles estavam cumprindo uma espécie de missão pública e civilizatória, embasada naquilo que fosse oportuno usar do conhecimento médico: o combate das epidemias; do saber jurídico: na criação de leis reguladoras dos bons costumes; e, do saber dos engenheiros remodeladores: obras que expressavam bom gosto e funcionalidade da cidade (SILVA, 2013a).

E com todas as leis e ações repressoras existentes no inicio do período republicano, os alvos preferenciais - e mais afetados - serão certos tipos sociais que se enquadravam na genérica conceituação de "classes perigosas", termo que ecoava amiúde no discurso policial e, principalmente, nos jornais daquele período. Era forte a crença de que pessoas vadiassem (artigo 399), praticassem a mendicância quando válidas (artigo 393), caíssem na prostituição ${ }^{1}$ e na embriaguez (artigo 396) nada mais eram que "opções" pela contravenção, porta de entrada para crimes mais graves (MENEZES, 1996).

No caso acreano que daremos ênfase, esses sujeitos são homens e mulheres que nas suas andanças, fazeres e prazeres entraram em conflitos com a ordem social, policial e moral. Muitas eram pessoas que tinham práticas e hábitos que se tornaram objetos de repulsa e desejo de eliminação daquilo que se imaginava para ser o adequado nas cidades que se buscava civilizar e ordenar de acordo com os princípios "corretos".

1 A prostituição não estava tipificada no Código Penal de 1890, mas enquadrava-se comumente no artigo 399 por ser uma "ocupação ofensiva a moral e aos bons costumes". 


\section{Imagens e discursos acerca dos "desviados" no Acre}

Nesta ótica citadina em que prostituição, embriaguez e vagabundagem tornam-se preocupações centrais das autoridades policiais nos anos iniciais da Primeira República, o Acre Federal tem os seus primeiros anos de organização político-administrativa marcados pela tentativa de se estabelecer um olhar vigilante e disciplinador dos espaços públicos e de suas gentes, principalmente aquelas oriundas dos estratos mais baixos da sociedade. A polícia (delegados e agentes) era o elemento mais presente no cotidiano dos "desviantes" da ordem e moral pública, fossem eles esporádicos ou costumeiros.

São muitos os casos que esses desvios das normas de "bem viver" aparecem em jornais, em inquéritos e em processos criminais, embora muitas vezes sejam apresentados de maneira lateral e secundados pela notícia principal do réu/vitima que se envolvia em outras letras do Código Penal: homicídios, agressões físicas, tentativas de assassinatos, furtos, etc. algo como: "o vagabundo fulano de tal assaltou uma casa comercial"; "mundanas são presas por agressão contra freguês em bar"; "vizinha denunciada por atentado ao pudor" e assim por diante.

Temos diversos casos assemelhados e descritos amiúde no jornal Folha do Acre, na sua coluna policiaes. Um relato no principio de 1911, mas que trazia uma notícia do final do ano anterior, conta que a "desabusada (sic) abelha cancellista Maria Júlia quis passar um natal turbulento na [Vila] Empreza² e assim foi parar na Mucura [cadeia], 2 A historiografia oficial aponta que a "fundação" da atual cidade de Rio Branco ocorreu em 1882, quando o seringalista Neutel Maia chega à região localizada na margem direita do Rio Acre e estabelece o Seringal Volta da Empreza. Aos poucos, a sede desse seringal vai ganhando ares de pequeno povoado e passa a ser denominado pelos moradores de Vila Empreza e em 1903, com a ocupação militar do Acre Setentrional, passa a ser chamada oficialmente de Vila Rio Branco e torna-se sede da prefeitura do Departamento do Alto Acre (1904-1908). O certo é que o nome oficial passa a conviver de maneira concomitante com o antigo nome. Por isso, em muitos jornais da época, cartas e outros 
donde só saiu no dia seguinte". ${ }^{3}$ O tom é irônico e permeado de gírias da época, a começar pelo termo abelha que faz alusão à mulher livre, solta, que vai para onde quer e a qualquer momento. É um termo que procura de maneira pejorativa indicar ser Maria Júlia prostituta e, por cima, uma abusada sem "bom senso". Algo que se reforça com o adendo de cancellista, pelo fato das prostitutas no período ficarem muitas vezes postadas nas cancelas (rótulas) ou janelas das casas, voltadas para rua, anunciando que ali se ofereciam serviços sexuais pagos (SCHETTINI, 2006).

Nesse mesmo dia, o referido jornal aponta que um sujeito chamado João Sant'Ana foi preso por tentar "disparar um revolver no frontispício de Maria Prego, vulgo Madame Tracajá. Resultado: a polícia agarrou-o e fel-o ir bater com os costados nas grades do xilindró". Não há maiores detalhes sobre as motivações das agressões de João contra a mulher duplamente apelidada: Maria Prego/Madame Tracajá. Os apelidos jocosos e irônicos sempre foram práticas corriqueiras usadas pelos jornais da época para "apresentar" à sociedade os criminosos, desviantes e sujeitos pobres que fugiam aos padrões estabelecidos de legalidade, moralidade e costume. Algo que já estava assentado numa larga cultura literária elitista originada em fins do período medieval e início da Era Moderna na Europa (GEREMEK, 1995).

Ainda neste apanhado da edição do primeiro dia do novo ano de 1911, o Folha do Acre traz a noticia que o delegado "passou um

documentos aparece comumente o nome de Cidade da Empreza em vez de Rio Branco, nome que não "pegou" de imediato. Passando a ser corrente o nome atual após a unificação dos quatro Departamentos implantados em 1921, quando Rio Branco se torna capital do Território Federal do Acre (PMRB, 2013).

3 Policiaes. Folha do Acre, $01 \% / 01 / 1911, \mathrm{n}^{\circ} 18$, ano I, p. 03. Este jornal circulou no Acre entre 1910 e 1949 e era ligado ao grupo político do coronel Antônio Antunes de Alencar, ex-prefeito do Alto Acre (1907-1908). Na sua fundação, foi "inaugurada" uma foto do ex-prefeito na sala redação do jornal. 
formidável pito nas divertidas Joanna Bezerra de Araújo e Benta Maria da Conceição que andaram aos supapos (sic) no Hotel Madri”. ${ }^{4} \mathrm{O}$ motivo desta confusão, atesta a folha, era a disputa pela "plata de um boliviano baludo". Ou seja, as divertidas entraram em discórdia ao se estabelecer uma espécie de disputa para ver quem iria botar as mãos no dinheiro de um estrangeiro, o que acabou não ocorrendo. Porém, desfecho diferente se deu no caso a seguir.

Neste referido hotel, cerca de três meses depois, o Folha do Acre aponta que Armando de Almeida Lobo estava almoçando na companhia "das meretrizes Amélia Pinto, Mayote e Izabel Ferreira". ${ }^{5}$ Após o almoço todos se dirigiram "aos aposentos da primeira d'essas mulheres, no mesmo hotel, a fim de beberem champagne". O caso se torna "policial" a partir do momento que Armando Lobo percebe que teve seu "anel de pharmaceutico" - deixado em cima de uma mesa - subtraído no momento em que se preparava para deixar o quarto de hotel onde se encontrava em deleite e libações com as três mulheres. Consta que após tomar conhecimento o delegado "tomou as devidas providencias" e abriu "um rigoroso inquérito a fim de apurar a verdade, já tendo sido ouvidas várias testemunhas". Não ficamos sabendo o que ocorreu após a confusão no Hotel Madri: se houve roubo, se alguém foi preso ou até mesmo se o anel recuperado pelo farmacêutico.

Este era um dos únicos e o mais famoso hotel da Cidade da Empreza (Rio Branco) à época, que nos dizeres do poeta Océlio de Medeiros "um anúncio novo, afixado numa das prateleiras melhor o define:

4 Em propaganda exibida no jornal Folha do Acre, assim era descrito o Hotel Madri, de Manoel Rodrigues: "prepara, banquete, lunchs, chocolates, etc. sortimento completo de bebidas nacionais e extrangeiras, como sejam: champanhes Cliquot, ditas portuguesas, vinhos Pomard, Beaunet, chiantes e muitos outros. Únicos recebedores aqui do especial vinho de meza Flor de Lis". Folha do Acre, 19/03/1911, n 29, ano I, p. 04.

5 Policiaes. Folha do Acre, 13/03/1911, nº 28, ano I, p. 02. Acervo da Biblioteca Nacional. 
hotel familiar... Outro, escrito em letras vermelhas o completa: 'só é permitida a entrada de mulheres depois das dez horas" (MEDEIROS, 1942: 168). Se existia tal alerta de verdade, não importa. Importante é destacar que no imaginário de pessoas como Océlio de Medeiros, o local era conhecido por ser frequentado por prostitutas que adentravam aos quartos de hospedes ali em transito ou por pessoas da sociedade local que ao irem comer e beber no restaurante do Hotel Madri, podiam também desfrutar de outros prazeres nos quartos daquele ambiente dito familiar.

Para além do espaço dos hotéis, bares e prostíbulos, havia ainda casos relatados de atentado ao pudor causado pela presença de mulheres pouco afeitas em manter a "boa moral", como o caso que veio à tona no jornal Folha do Acre. Anna Rosa, dita vizinha de Francisco Costa, foi denunciada por este porque "vinha offendendo constantemente à moral e priva a família do queixoso de sahir á janella de casa". ${ }^{6}$ Não se tem mais detalhes acerca dos atos cometidos por Anna Rosa, mas o fato é que seu vizinho se "ofendeu" pela presença indesejada da Anna e quis preservar a sua família de tal "agressão" tornando o caso objeto de ação policial e levado ao público pelo jornal Folha do Acre.

\section{Trabalhadores em zonas cinzentas: fronteiras tênues do correto e do errado}

Havia também ocorrências onde homens trabalhadores, ao se verem com dinheiro em mãos, logo acorriam aos locais onde se encontravam as abelhas da cidade. Como é o caso relatado abaixo em matéria do periódico Folha do Acre:

Os fretadores da lancha Silvério Nery, srs. Fernandes \& $C^{\mathrm{a}}$, segunda-feira ultima, andaram ás voltas com o pratico d'essa embarcação, Sr. Euzébio Galvão de Caldas, arvorado a commadante. Os tripu-

6 Policiaes. Folha do Acre, 13/03/1911, nº 28, ano I, p. 02. Acervo da Biblioteca Nacional. 
lantes da Sylverio Nery, por sua vez tentaram jogar as cristas com o Ozebio. Para por termo a essas continuas desintelligencias, os srs. Fernandes \& Cia. convidaram o improvisado commandante a deixar o exercício d'essas altas funções. Accedendo ao convite, Ozebio metteu-se no cobre que lograra saldar e passou um recebido dando plena e geral quitação aos fretadores da Sylvério Nery. ${ }^{7}$

Pela noticia, ficamos sabendo que o piloto de uma lancha, que em tom galhofeiro é tratado por Ozébio e alçado à condição de comandante, quase foi preso por desviar-se de suas funções e não cumprir as obrigações contratuais com os passageiros que tinham alugado a embarcação da firma na qual o acusado trabalhava.

Mas o caso não se encerra somente aí, pois Euzébio...

Cahiu, porém, na esparrela de entrar no botequim Pau de fogo, onde se reúnem as mais chics abelhas da cidade, e... ficou na chinella. No dia seguinte pensou como obter mais plata e por mais que puchasse pela imaginação só encontrou um meio: fazer os srs. Fernando \& $\mathrm{C}^{\text {a }}$ escorropicharem mais dinheiro, sob pena de serem perseguidos pela Capitania do porto. Achou prudente que devia antes de tudo levar uma queixa á polícia e assim o fez. O tenente Paes Barreto, delegado de polícia, syndicou do facto e depois de apurar a verdade, por um triz não metteu o Ozébio nas grades. ${ }^{8}$

Ao ser despedido pelos donos da lancha Silverio Nery, Euzébio Caldas com o dinheiro recebido pela indenização da firma foi atraído para curtir os prazeres existentes no bar Pau de fogo. Ambiente que o jornal procura colocar a etiqueta de local de prostituição e onde Euzébio Caldas teria gastado até seu ultimo centavo, só saindo de lá pela manhã. Quase foi preso, talvez isso não tenha ocorrido porque muitos sabiam - e o próprio jornal atesta isso - ser o "comandante" Euzébio um homem trabalhador que momentaneamente saiu da "linha" e caiu

7 Policiaes. Folha do Acre, 07/05/1911, n³ 36, ano I, p. 02. Acervo da Biblioteca Nacional.

8 Policiaes. Folha do Acre, 07/05/1911, n 36, ano I, p. 02. Acervo da Biblioteca Nacional. 
na farra, momento em que se deparou com o olhar "vigilante" do delegado e militar Paes Barreto.

Temos nessa mesma edição a informação de que foram presas três mulheres por questões relacionadas com dívidas: "Por questões de paga não paga, as horizontaes Beatriz Bisleri, Lili Cadini e Antonia Barrabás, andaram pela polícia, onde quasi se diplomavam, mediante os trinta fachos que o carcereiro Fernandes não dispensa". "Horizontal" era uma expressão bastante usada para se referir às prostitutas, que neste caso envolvem-se em uma confusão para saberem que iria pagar uma conta contraída pelas referidas mulheres. É o que sugere o jornal.

Contudo, o olhar da polícia sobre mulheres conhecidas como "horizontais", "abelhas" e outro termos correlatos, era tão frequente e cotidiano que ensejava lidar com alguns casos com o descrito abaixo.

No famoso botequim Novo Progresso, no bairro Rio Branco, deu-se há dias uma encrencagem d'arromba. Ao toque do piano, a senhorêta Xico festejava alli mais um botão que colhera no jardim de sua preciosa existencia, na phrase burilada e sonora do comandante da lancha Dita, cidadão Joaquim da Silva Mattos, que a encaizilhou num dos substanciosos brindes que fez á anniversáriante.

Outra vez temos um comandante de embarcação envolvido em um caso destacado como havendo presente algumas prostitutas e tendo como cenário o espaço de um bar dito famoso na capital do Departamento do Alto Acre. Uma delas a aniversariante, para quem o empolgado comandante remetia discursos e brindes efusivos. Vale lembrar que a cidade era um importante local de trafego de gentes e mercadorias que provinham de outras cidades acreanas, Manaus, Belém e Rio de Janeiro. A área portuária era próxima aos mais famosos botecos, hotéis, pensões e prostíbulos, como de praxe em muitas outras localidades com características semelhantes: Rio de Janeiro, Belém, Manaus e outras. 
Havia muita gente na festa. As 10 horas e entusiasmo foi levado ao seu auge. $\mathrm{O}$ embarcadiço discursador estava radiante na deslumbrancia das deliciosas ilibações que fizera. De repente, dobrou a toda o cabo das arrelias. O delegado, tenente Paes Barreto, porém, pôz-lhe embargo ás violentas manobras, chamando-o a ordem. O Zacharia, que estava fora, na rua, serenando o forró, vendo que tudo reentrara em seus eixos, devido a intervenção de auctoridade, continuou a assobiar a Dalila, burguezmente. Quando estava assim correndo a festa, nova encrencragem se deu: a senhorêta Marie Affonse, vulgo Mayote, enthusiasmou-se demais... O tenente Paes Barreto mandou guindal-a.

A mulher chamada em tom de deboche de "senhorêta Xico" estava junto aos demais, comemorando seu natalício, quando chegou ao recinto o delegado e militar Paes Barreto. O fato de o jornal destacar o horário denota que havia um limite de tempo para que daí em diante a autoridade pudesse intervir mesmo que não estivesse ocorrendo nenhum delito. Talvez em nome do silêncio, prevenção aos bons costumes e controle dos "excessos" que poderiam ser cometidos por essas pessoas geralmente vistas como prostitutas, vadias e bebuns contumazes ou esporádicos.

Percebemos que não houve, pelo menos neste caso, o silencio e aceitação passiva das pessoas que se encontravam no bar Novo Progresso. Existiram protestos e resistências, que foram reprimidas pela autoridade do delegado que certamente se fazia acompanhar de algum soldado the dando apoio.

Trinidad Mercado, outra graciosa senhorêta, conviva do baile, protestou formidavelmente contra a recambiação de sua companheira, temendo um futuro flagrante que talvez fosse lavrado contra a mesma, por tentativa de... attentação, com grave risco de sua liberdade por dilatados annos. A protestante arreliou se contra auctoridade enquanto o Zacharias, muito a surdinas, sahia pela visinhança em busca de quem lhe explicasse caso juridicamente. Pode ou não pode prender? Perguntava elle. Há ou não há motivo pra o flagrante? Insistia com ares acadêmicos. Em frente ao 6 de agosto alguém so- 
pro-lhe ao ouvido uma resposta que o deixou estupefacto. Zacharias abandonou a causa...

A chegada repentina da autoridade policial foi, segundo o jornal, o estopim de protesto contra o fim da festa e das prisões efetuadas de imediato pelo delegado Paes Barreto. A primeira delas foi da aniversariante, sob protestos de sua companheira Trinidad Mercado também ameaçada de ir para trás das grades. Outros, como Zacarias, procuraram sair à francesa para não cair nas garras da autoridade que zelava pela ordem urbana da pequena cidade acreana.

Mas... vistos os autos do ocorrido, foi essa: Mayotte e Trinidad sejam mettidas em custódia por 24 horas consecutivas de acordo com o código, constituição e demais leis do paiz. Como não se conformasse com tal decisão, o exaltado commandante da Dita, a favor das pacientes, interpoz immediatamente habeas corpus, sendo este recebido apenas no efeito recambiativo. Sentença final: os três - recorridas e recorrente - foram sem mais agravo para o novo xilindró da polícia, onde cumpriram a pena e pagaram ás custas ao... carcereiro. ${ }^{9}$

Resumo da ópera: duas mulheres presas e, por se exaltar na defesa das mulheres, o dito comandante. O fecho irônico do jornal procura indicar de maneira dúbia que todos os três foram "acertar" as contas com o carcereiro da cadeia pública. A cidade vigilante mais uma vez pôs termo na cidade divertida e dos prazeres.

O poeta e funcionário público Océlio de Medeiros viveu em Rio Branco algumas décadas depois desses acontecimentos narrados nos jornais em suas colunas policiais. Com fama de boêmio contumaz e farrista, mas não de malandro e vadio, pois não era "um qualquer", figura conhecida, funcionário público e com "endereço certo e sabido", Océlio de Medeiros que nessa região do Segundo Distrito da cidade "estão as pensões, as casas de jogos, o beco do meretrício e o Hotel

9 Cadastro policial: carraspanas e arrelias, distúrbios e... xilindró. Folha do Acre, 07/09/1911, nº 51, ano II, p. 03. Acervo da Biblioteca Nacional. 
Madri”. Esse lado da cidade, na sua visão, contrastava com o Primeiro Distrito, do outro lado do Rio Acre: local ordeiro e pacato, respeitável e pacifico, pois ali estão localizados "o Palácio do governo, a Matriz, o Fórum a Polícia, o Obelisco (...) aí moram as principais famílias" (MEDEIROS, op. cit., p. 109). Uma cidade dividida, não só pelo rio. Um lado bom, moralista e respeitável; o outro, mau, degradante, cheio de vícios e perdições.

Outro escritor, chamado Abguar Bastos escreveu uma obra intitulada Certos caminhos do mundo, que parece ser a fonte de inspiração para Océlio de Medeiros. A obra foi publicada no ano de 1936 e em certa passagem da obra ele diz:

Empresa é o lado do comércio. Antigo seringal elevado ao poderio de parte oriental da cidade. Pedaço de terra livre, não se apega a preconceitos. Uma excitante vida noturna. Aos domingos funciona um cinema. Vêm-se marafonas enchapeladas nos camarotes e senhoras honestas, afrontadas, timidamente, nas cadeiras de fila. Cruzam-se nas ruas o rebanho e a matula, profissionais do jogo, "camelots", ganadeiros, marítimos, contratadores de seringa, contrabandistas, vendedores de coca. Ferozes malsinações escapam dos becos e nas vielas há um crescente rumor de escândalo e vícios (BASTOS, 1936: 66).

Essa cidade de dois lados complementares e diferentes era a característica marcante na visão desses dois escritores. Para Abguar Bastos, a "parte boa" da cidade, mesmo em aparente contragosto, tinha que conviver com aquilo que percebia como seu oposto. Mulheres "honestas", donas de casa e casadas se defrontando em mesmos ambientes com as "abelhas" e "mariposas" que certamente sabiam de como era aparente aquela sociedade que elas teimavam em "aviltar" com suas práticas, jeitos e trejeitos.

No mesmo tom, homens em negócios escusos e ilegais procuravam encontrar vítimas, "fregueses" e parceiros para lucrarem algum 
dividendo e irem sobrevivendo diante de uma ordem urbana que era confrontada com o que ela mais renegava: os indesejados sociais.

Havia ainda crimes passionais, cometido por homens que não eram tidos como pertencentes aos grupos dos indesejáveis, mas momentaneamente quando folgavam em seus afazeres laborais frequentavam prostíbulos e bares, onde se envolviam e confusão e acabavam presos. O caso abaixo exemplifica bem isso.

As $16^{1 / 2}$ horas do dia 28 do mez homtem findo, no beco da fabrica, á residência das mudanas Senhorinha Arruda e Julia Maria dos Santos, conhecida por Flagelada, Abdoral Lima, de 18 annos de idade, solteiro cearense, motorista empregado no seringal Catuabá tendo ouvido de Senhorinha que Julia amava outro homem, deixou-se possuir pelo ciúme, tendo bebido com as referidas mudanas alguns grogs de cognac, puxou o seu revolver Mauser; manejando-o contra Julia. Senhorinha tomou a frente mas com tanta infelicidade que o fez precisamente quando a percussão do cartucho se verificava, recebendo assim, no braço o projectil que varando-o de lado a lado foi-se alojar na parte inferior da cavidade abdominal da inditosa Julia. Perseguindo pelo clamor publico, o delinquente foi preso em flagrante, na rua Plácido de Castro, próximo á rua Abunã. Confessou o crime. Populares conduziram Julia á Pharmacia Ocidental, onde uma hora depois, receberam os primeiros cuidados médicos. Julia Maria dos Santos falleceu antehomtem, ás 22 horas. $^{10}$

Temos um crime cometido por um jovem trabalhador enciumado, porque segundo o jornal não era correspondido no amor que tinha por uma "mulher da vida". O ato passional, talvez encorajado pelo álcool, leva Abdoral às barras da lei ao assassinar Julia Maria dos Santos.

Um crime em que estão presentes aspectos relacionados à moral, honra e costumes de uma sociedade marcada por profundos aspectos relacionados ao universo da masculinidade e do patriarcalismo. Mesmo um homem pobre e simples, como Abdoral, compartilhava de tais

10 Um tiro, duas victimas. Folha do Acre, 01/11/1917, $\mathrm{n}^{\mathrm{o}} 210$, ano VIII, p. 02. Acervo da Biblioteca Nacional. 
valores: viu-se ofendido pelo desprezo de uma mulher, e prostituta, quando resolveu "lavar sua honra com sangue" daquela que o rejeitou.

Outro centro urbano importante do Departamento do Alto Acre era a cidade de Xapuri, localidade que o primeiro prefeito do Departamento do Alto Acre - o médico e militar Raphael da Cunha Mattos - intentou elevar à condição de sede da prefeitura em 1904. Ele considerava esse pequeno núcleo urbano mais salubre e em condições climáticas superiores à Rio Branco.

Ali, em 1913, o jornal o Alto Acre relata um crime - entre outros de roubos e assassinatos - cometido por um sujeito misterioso que é comparado ao celebre Jack Estripador. Consta que

sábado, á meia-noite, mais ou menos, a mulher de vida alegre de nome Lica, foi despertada debaixo de socos por um individuo mascarado que depois surrou impiedosamente com uma bengala de ferro. A infeliz lutou com desespero e o miserável e covarde agressor deixou parte da barba falsa, chapéu, botões de punho e a bengala que se acham na polícia. Diz a pobre mulher que deu uma dentada no braço de seu algoz.11

Temos o caso de um agressor anônimo a quem se atribui a suspeição de outros delitos misteriosos ocorridos na pequena cidade de Xapuri. No caso acima, há agressão de uma mulher identificada como prostituta, pois é de "vida alegre".

Outra mulher, chamada Maria Bibiana, foi presa cerca de três anos depois e acusada de ofender a moral pública num local chamado de Mangueira onde na "porta do açougue, para mais uma vez, exibirse, proferindo palavras injuriosas, ao encarregado da venda de carne verde (...) razão porque passou a noite no pequenino xadrez". ${ }^{12} \mathrm{Me}-$

11 Quem foi? Alto Acre, 15/06/1913, nº 01, ano I, p. 01. Acervo Museu Universitário da UFAC

12 Notas policiaes. Comércio do Acre, $02 / 04 / 1916, \mathrm{n}^{\circ}$ 44, ano I, p. 03. Acervo Museu Universitário da UFAC 
ses depois, a mulher chamada Raymunda Chaves Albuquerque, vulgo, Doninha, sofreu uma tentativa de assassinato por seu indigitado amante "o moreno Cyrillo Borges, alfaiate, conhecido por dr. Agulha" que em posse de uma navalha tentou retalhar Doninha. A vítima foi quem acabou presa e assim se reporta o jornal: "por ofensas a moral e desrespeito a autoridade de permanência, foi presa a horizontal Doninha, que gramou apenas 15 horas de xadrez". ${ }^{13}$

\section{Inquéritos policiais e processos criminais: os "desviados" diante da justiça}

As desavenças envolvendo pessoas durante o consumo de bebidas alcoólicas eram geralmente relatadas em jornais e alguns casos mais graves chegavam às barras da Justiça. Na Vila de Porto Acre, José Moreira de Carvalho em 08 de setembro de 1909 encontrava-se na taberna de Alfredo Gathay onde também estava Francisca Julia, que teria oferecido a ele um copo de cerveja e ao se recusar a beber, Francisca Júlia derramou o copo de cerveja em cima de José Moreira. ${ }^{14}$

Logo em seguida José Moreira teria, segundo os autos, partido para cima de Francisca Júlia esbofeteando-a, quando chega à taberna José Correia de Lyra que presenciou o ataque de fúria de José Moreira e partiu pra defender Francisca Julia dando um soco em José Moreira, que no mesmo instante se retirou do local, retornando momentos depois armado de um terçado com o qual agrediu José Correia de Lyra, lhe fazendo vários ferimentos. Nesta ocasião estava ainda presente José Antônio Viera, que deu voz de prisão ao agressor que foi encaminhado para a delegacia da vila.

13 Notas policiaes. Comércio do Acre, 17/09/1916, nº 68, ano I, p. 04. Acervo Museu Universitário da UFAC.

14 José Moreira de Carvalho, réu; Inquérito Policial, Juízo do $1^{\circ}$ Termo Comarca do Alto Acre, $n^{\circ}$ 12/1910, 29 p. CDH/TJAC. 
Neste mesmo dia, o subdelegado Octavio Chaves ouve o depoimento de Francisca Julia, mulher de 24 anos, solteira, natural do Rio de Janeiro, e declarada com mulher de "profissão duvidosa". Ela relatou que estava na taberna de Gathay quando ofereceu um copo de cerveja para José Moreira, sendo que ao recusar - e ela dizer "ter grande intimidade" entre eles -, Júlia confirma ter derramado um copo de cerveja em cima de José Moreira. O restante da estória, ela descreve como já descrito acima: José Moreira deu-lhe uns tapas e José Correia de Lyra entrou para defendê-la.

Também prestou depoimento o carioca de nome José Antônio Vieira, que se declarou solteiro, com 27 anos e morador daquela localidade. Ele atestou que viu quando Francisca Júlia derramou um copo de cerveja em José Moreira de Carvalho. Por isso este partiu para bater na referida mulher, momento em que foi repelido por José Correia de Lyra que na ocasião deu-lhe uma bofetada, o agredido logo em seguida retirou-se do local, retornando mais tarde armado de um terçado e travou luta com José Correia de Lyra que saiu ferido.

Após ouvir todos, o subdelegado publicou nota de culpa e Jose Moreira de Carvalho foi pronunciado e seu inquérito enviado à justiça. Contudo, a fiança de José Moreira de Carvalho foi fixada em duzentos mil réis, valor que só foi depositado pelo acusado nos cofres da Mesa de Rendas do Acre no dia seguinte, quando foi solto e ganhou a possibilidade de responder em liberdade pelo crime de "ferimentos leves",15 obrigando-se a comparecer até o final do julgamento, independente da hora citada, sob as formas da lei. Somente em março de 1915, seis anos depois do acontecido no bar de Gatahay, o processo foi arquivado.

15 Código Penal de 1890, Art. 303. Ofender fisicamente alguém, produzindo-lhe dor ou alguma lesão no corpo, embora sem derramamento de sangue: Pena - de prisão celular por três meses a um ano. 
Nessa mesma vila, no ano seguinte, foi registrado um caso que chama a atenção, pois envolve questões familiares relacionadas à honra e aos modos de "bem viver". Anna Barbosa Cordeiro perdeu a guarda da filha ao ser acusada perante a justiça. $O$ escrivão atesta em sua peça documental que Anna Barbosa era uma mulher de "irregular procedimento", mãe de uma filha chamada Júlia Barbosa Samico de 14 anos. Ou seja, o ambiente familiar é considerado impróprio para a permanência de Júlia Samico junto à sua mãe e seu companheiro Raimundo, duas pessoas de procedimentos "desviados" pela embriaguez.

E vive explorando a inocência dessa criança para usufruir dela tanto assim que pedida em casamento, não tem querido ela o seu consentimento. Forçando a mesma menina a querer fugir de casa pra evitar os desastres quem em sua honra possa assim com a especulação de sua mãe, que segundo me informaram dar-se ao vicio de embriaguez é vive com um homem de [má] nota.16

Em 11 de Abril de 1910, no cartório de Porto Acre, foi entregue em "termo de depósito" Júlia Barbosa para o casal Antônio Hipólito da Silva e Arnalda Leopoldina da Silva, considerado como sendo de boa reputação, para ficar responsável por ela e sendo "obrigados a zelar pela mesma e por sua honra e considerá-la como filha" até que o juiz de órfãos resolvesse a situação de Júlia Samico, pois com sua mãe não poderia mais ficar convivendo dali em diante.

Dias depois de Júlia ser entregue a um casal "honrado" e respeitado naquela vila, o comerciante Simplício Lemos Vasconcelos vai ao cartório para pedir Júlia em casamento. A menor é ouvida e aceita o pedido, conforme descrito abaixo.

Diz Simplício Lemos Vasconcelos, cidadão brasileiro e comerciante nesta Vila de Porto Acre que pretendendo se casar com Julia Barbosa Samico, menor que se acha depositada em poder e casa de Antônio Hipólito da Silva. Como vem dizer, querendo casar-se com a

16 Anna Barbosa Cordeiro, ré, Autos Cíveis de Deposito de Menor Julia Barbosa Samico, Juízo do $1^{\circ}$ Termo Comarca do Alto Acre, n³6/1910, 22 folhas. CDH/TJAC. 
mesma menor e dela tendo consentimento antes de ser a mesma depositada solicitou licença da mãe que a nega em justa causa. Requer que seja ouvida a menor. Aos vinte seis dias do mês de abril do ano de mil novecentos e dez, perguntada se era verdade que sua mãe a maltratava e opunha-se a seu casamento respondeu que sua mãe não a maltratava de pancadas, mas normalmente e tendo ela sido pedida em casamento por quatro pretendentes sucessivamente deixaram de casar-se. Que sua mãe é dada ao vicio da embriaguez e nas alcoólicas, desfaz sempre os contratos de casamento e que ela respondente estava disposta a sair de casa porque o amante da sua mãe, de nome Raimundo de vez em quando dava no rosto dela. Perguntada se era do seu gosto casar-se com Simplício Lemos Vasconcelos, respondeu que sim, pelos maus tratos que recebia na casa materna.

Com se percebe, em seu depoimento Júlia Samico reforça a acusação contra sua mãe e vê o casamento como uma saída da situação em que se encontrava, inclusive sofrendo violência por parte do amante de sua mãe. No dia 27 de abril do mesmo ano foi expedido o alvará de licença para que Júlia Samico se casasse com Simplício Lemos. Com este caso, podemos perceber que uma pessoa ser vista como dada ao vício da embriaguez trazia muitos transtornos para si, pois atravessava aspectos relacionados a honra, moral e bons costumes e poderia ocasionar a perda da guarda dos filhos por parte de pais como ocorre com Anna Barbosa.

Ser vadio (não ter emprego) também era uma mácula grave. A vadiagem era vista como a porta de entrada para assaltos, roubos e furtos pelo fato do individuo não ter trabalho "honesto" e regular, viver na rua e em bares, sem dinheiro, sem ter como se alimentar, tendo que viver da caridade de algumas pessoas. Com isso entendia que a saída de alguém nessa situação era praticar delitos, como foi o caso de "Antônio Rogers de Souza, acusado de furtar ${ }^{17}$ no dia 16 de julho de

17 Art. 330: subtrair para si, ou para outrem, coisa alheia móvel, contra a vontade do seu dono: (...) $4^{\circ}$ si de valor igual ou excedente a 200\$000: Penas de prisão celular por seis meses a três anos e a mesma multa. 
1908, em Porto Acre, uma certa quantia em dinheiro da casa de Moisés Bendalian". ${ }^{18}$

No dia seguinte, Antônio Rogers de Souza foi intimado a comparecer na Delegacia Auxiliar para prestar esclarecimentos ao delegado Josias Lima. O queixoso era o comerciante paraense Moisés Bendalian, de vinte quatro anos e dito solteiro. Ele queixava-se do fato de Antônio Rogers ter entrado na sua residência por volta das oito horas da manhã. Afirmava que considerava até então o suspeito uma pessoa em que depositava confiança, por isso permitia que o acusado ingressasse na sua casa comercial e aposentos livremente.

Porém, algum momento depois dessa última visita de Antônio Rogers em sua casa, Moisés deu por falta da quantia de 530\$000 (quinhentos e trinta mil réis) que deixara no bolso de seu paletó, pendurado na sala de refeições. Para referendar suas suspeitas, ele diz que Rogers estava fazendo grandes gastos em casas comerciais e em uma casa de meretrizes de Porto Acre, local onde teria tirado do bolso cédulas $100 \$ 000$ e $200 \$ 000$, isso cerca de uma hora após Moisés ter dado por falta do dinheiro.

Ao depor, Antônio Rogers disse que havia trabalhado como empregado de um posto fiscal e perante o delegado tenta tirar a pecha de vadio, ao afirmar que "vivia atualmente de avaliações e causas de outras agências, que esteve realmente em diversos lugares da Vila". Confirmou ainda que frequentava sim a casa comercial de Moisés, onde por diversas vezes almoçou e jantou, por isso mostrava-se surpreso por conta da acusação de furto. Depois das declarações de Antônio Rogers, o delegado Josias Lima passou a ouvir as testemunhas arroladas no caso.

A primeira testemunha parecia ser bastante conhecida de Antô-

18 Antônio Rogers de Souza, acusado, Furto, Delegacia Auxiliar de Policia da Prefeitura do Departamento do Alto Acre, $\mathrm{n}^{\circ} 153 / 1908,52$ folhas. CDH/TJAC. 
nio Rogers. Chamava-se Gervásio de Farias Moraes, de 43 anos, que morava numa mesma casa com Antônio Rogers e disse:

ontem as nove e meia ou dez horas da noite foram em sua casa chamá-lo um criado do Dr. Rebello e Júlio de tal, dizendo antes que fosse buscar Antônio Rogers de Souza seu companheiro de casa que andava embriagado e caído na Avenida Sete de Setembro, tendo em seu poder bastante dinheiro. Foi por ele Rogers convidado a tomar cerveja, o que recusou, que no mesmo dia pela manhã Rogers chegou em casa e mostrou-lhe algumas cédulas de cujo valor não pode observar. Disse mais, que o referido Rogers está desempregado e não lhe consta que houvesse recebido dinheiro por serviços prestados a qualquer que seja estranhando ter ele apresentado com tanto dinheiro.

Depois, foi a vez de Joanna Araujo depor, que se atestou ser potiguar, com vinte e seis anos, moradora de Porto Acre, solteira e, segundo o escrivão, mulher "dada aos costumes". Ou seja, uma forma sublimada de referir-se a atividade de prostituição. Segundo consta, ela disse que Antônio Rogers esteve na sua casa no mesmo dia do furto, por volta das oito horas da noite mostrando-lhe um maço de cédulas, cujo valor não sabia precisar e que ele convidou-a para tomar champanhe e cerveja, pois o mesmo "disse ter dinheiro para pagar". Porém Joanna afirma que o convite foi recusado por ela, falando também que ignorava a profissão de Rogers, sabendo apenas que ele estava desempregado. Ou seja, a primeira testemunha deixa a situação de Rogers pior do que já estava. Como poderia alguém desempregado e sem posses materiais estar gastando uma vultosa quantia de uma hora para outra com cervejas, champanhes e tendo outros desfrutes em casa de mulheres "dadas aos costumes"?

A outra testemunha foi Maria Raimunda do Nascimento, natural do Ceará e com vinte e dois anos de idade. Ela conta que já estava recolhida em seu quarto quando Antônio Rogers chegou na sua casa na noite do dia 16 de julho, oferecendo bebidas à sua amiga Joanna, que 
teria recusado a oferta. Foi quando ouviu Rogers atestar que tinha dinheiro para pagar as despesas. Ela ainda falou que já tinha encontrado com Rogers, pela manhã do mesmo dia, no estabelecimento comercial de uns "turcos" onde ele se ofereceu para pagar um guarda sol que ela havia comprado na ocasião. Maria Raimunda diz que na mesma hora recusou justificando ter clareza que Rogers era um homem desempregado. Por esse fato, disse desconfiar da procedência do dinheiro que ele tinha e assim não quis receber a prebenda ofertada pelo acusado.

A partir dessa testemunha, podemos inferir que Maria Raimunda se enquadrava na conceituação vigente à época de mulher "dada aos costumes", pois morava numa "casa de meretrizes" conforme atesta Moisés Bendalian em seu depoimento ao acusar Antonio Rogers. Interessante perceber que as duas mulheres, embora tivessem a pecha de prostitutas e sofressem preconceitos, em seus depoimentos procuram se distanciar das "facilidades" oferecidas por um "desocupado/desempregado". Portanto, se recusam a admitir aceitar benefícios vindos de um dinheiro obtido de forma ilícita e origem incerta.

$\mathrm{O}$ advogado de origem mineira Jerônimo Moreira Benvindo, de 34 anos, também foi testemunha. Ele falou que estava se dirigindo ao Hotel do Rebello para jantar quando viu Antônio Rogers alcoolizado com uma ou duas cédulas de $100 \$ 000$ e percebeu que na ocasião ele pretendia pagar despesas que fizera no referido hotel naquela noite. Porém o dono do hotel resolveu descontar despesas feitas anteriormente, quando logo iniciou uma discussão entre Rogers e o dono do hotel, por conta deste ter abatido dividas antigas de Rogers. Malgrado esse deslize cometido pelo acusado, parece que ele era uma pessoa que até então tinha a confiança de alguns comerciantes da vila de Porto Acre. Essa afirmação se sustenta no fato de Rogers ter acesso livre a casa do seu acusador para comer e ter créditos na praça, como no caso do hotel. 
Com esses depoimentos não restavam muitas dúvidas da autoria do furto: todos estavam cientes de que algo errado havia com as gastanças repentinas de Antônio Rogers, um desempregado que de uma hora para outra adquire dinheiro sem explicação convincente. Os depoimentos o incriminavam, sua situação ficava difícil, pois ele não tinha como provar a origem do dinheiro que estava "gastando" e assim acabou fazendo provas contra sim próprio, sendo acusado e único suspeito pelo furto do dinheiro de Bendalian.

A conclusão nas páginas do inquérito policial é taxativa: "dos depoimentos nestes autos não há duvidas de que o delito tenha sido praticado pelo indiciado Antônio Rogers de Souza, pois apesar de não haver testemunhas do roubo em todo caso ele, um individuo desocupado e ébrio habitual, o que faz prova contra o mesmo Rogers". Ou seja, mesmo não havendo provas, somente indícios robustos, o determinante da certeza de culpa era a forma de vida que o acusado levava: ébrio contumaz e desocupado.

\section{Considerações finais}

Esses casos brevemente relatados expressam em parte como questões relacionadas à moral, valores sociais e normais legais eram compartilhados, negados, vividos e corporificados por diferentes sujeitos no Território Federal do Acre, mais especificamente do Departamento do Alto Acre. Uma sociedade multifacetada, com a presença de muitos migrantes oriundos das mais diversas partes do país e até estrangeiros. Homens e mulheres convivendo em vilas e florestas numa região recém-incorporada ao Brasil, cujo atrativo aos adventícios em muito se relacionava aos negócios da borracha ou à parca estrutura administrativa que começou a ser implantada após 1904.

Assim temos nordestinos, sulistas, portugueses, "turcos", bo- 
livianos, portugueses, indígenas e outras etnias\nacionalidades "fazendo" do Acre um caldeamento de vivencias e comportamentos que muitas vezes se chocavam com os valores considerados legais e normais. A presença do estado como ente que detém o monopólio legal da violência e é o ente reconhecido como arbitro de conflitos, conviviam com práticas baseadas em costumes não inseridos em bases do racional-legal e da impessoalidade.

MORAL AND DAILY LIFE: VAGRANCY AND PROSTITUTION IN THE DEPARTMENT OF ALTO ACRE (1904-1920)

\section{ABSTRACT}

This article aims to present an approach to vagrancy and prostitution in the Department of Alto Acre, within the period from 1904 to 1920, having documentary sources such as newspapers, police investigations and criminal proceedings. Addressing crimes such as vagrancy, drunkenness, crimes against honor and morality and good manners, those crimes and transgressions are articulated with the everyday life of the society from Department of Alto Acre in the indicated period, trying to bring a new look at these issues poorly explored by historiography and regional literature.

KEYWORDS: Department of Alto Acre. Crimes. Vagrancy. Prostitution. Criminal proceedings.

\section{REFERÊNCIAS}

BASTOS, A. Certos caminhos do mundo: romance do Acre. Rio de Janeiro: Hersen Editores, 1936.

FAUSTO, B. Crime e cotidiano: a criminalidade em São Paulo (1890/1924). São Paulo: Edusp, 2001.

GEREMEK, B. Os filhos de Caim: vagabundos e miseráveis na literatura europeia (1400-1700). Tradução de Henryk Siewierski. São Paulo: Companhia das Letras, 1995.

MEDEIROS, O. A Represa. Rio de Janeiro: Irmãos Pongeti Editores, 1942.

MENEZES, L. M. Os Indesejáveis: desclassificados da modernidade. Protesto, crime e expulsão na Capital Federal (1890-1930). Rio de Janei- 
ro: EdUERJ, 1996.

PMRB - Prefeitura Municipal de Rio Branco. A Rio Branco em que vivemos: registro histórico de 100 anos de prefeitura. Rio Branco: S. Ed. 2013. SCHETTINI, C. Que tenhas teu corpo: uma história social da prostituição no Rio de Janeiro das primeiras décadas republicanas. Rio de Janeiro: Arquivo Nacional, 2006.

SILVA, F. B. Representações do urbano e do rural no Território Federal do Acre (1904-1920) In: NASCIMENTO, L. M.; SILVA, F. B. (Org.). Cartografias Urbanas: olhares, narrativas e representações. Rio de Janeiro: Letra Capital Editora, 2013. p. 166-180.

SILVA, F. B. Acre, a Sibéria tropical: desterros para as regiões do Acre em 1904 e 1910. Manaus: UEA Edições, 2013. 